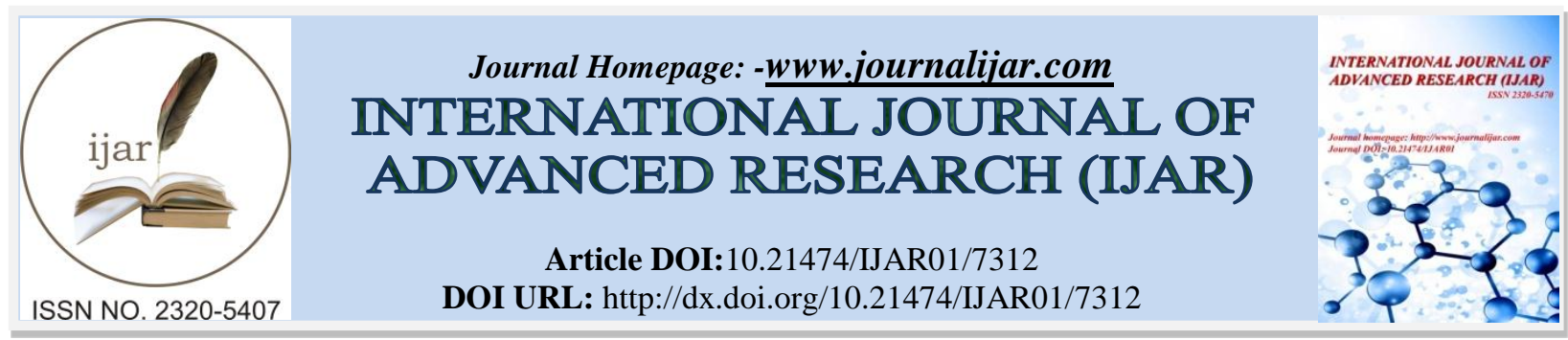

RESEARCH ARTICLE

\title{
THE EFFECT OF STARVATION ON HISTOLOGICAL AND IMMUNOHISTOCHEMICAL FEATURES OF THYMIC EPITHELIAL RETICULAR CELLS, USING CD326 MARKER EXPRESSION, IN NEWBORN MICE.
}

\author{
Huda Hussein Abd Fayr ${ }^{1}$, Haider A. Jaafar ${ }^{2}$ and Hussein A. Jarallah ${ }^{3}$. \\ Department of Human Anatomy, Section of Histology\& Embryology, University of AL-Nahrain, College of \\ Medicine, Baghdad, Iraq.
}

\section{Manuscript Info}

Manuscript History

Final Accepted: 20 May 2018

Published: June 2018

Key words:

Thymus gland, EPCAM receptor, RECs, cd326, newborn mice, starvation.
Received: 18 April 2018

\begin{abstract}
The thymus gland serves a role in the training and development of Tlymphocytes ( $\mathrm{T}$ cell), cells of thymic gland, have vital effect in proliferation, differentiation and maturation of $\mathrm{T}$ - lymphocytes. They secrete certain biomarker proteins on their cell surfaces called epithelial cells adhesion molecules (EPCAM). This study aimed to analyze the effect of starvation in newborn mice on anthropometric and immunohistochemical changes of reticular epithelial cell (RECs) on growth and development of thymus gland using anti EPCAM receptor 2 . The study design enrolled two groups; control groups consist of (20) newborn are sacrificed according to (1, 7, 14 and 30 days) each groups (5) litters and starvation groups consist of (15) newborn are sacrificed according to (7,14 and 30 days) each group (5) litters and ; the thymus glands are processed histologically and immunhistochemically to demonstrate reticular epithelial cells reactivity of EPCAM by applying Aperio Algorithm software. The EPCAM are expressed and present on cell membranes of RECs are decreased with the progress of starvation involving the whole layers of thymic tissue (subcapsular, cortical, cortico-medullary and medullary areas). This indicates that EPCAM is important in signaling, proliferation and differentiation of the progenitor migrating immature thymocytes so that be graduated as mature CD4 and CD8 T lymphocytes.

It has prognostic value in thymic tissue development, regeneration and normal epithelial homeostasis.
\end{abstract}

Copy Right, IJAR, 2018,. All rights reserved.

\section{Introduction:-}

The thymus is an essential component of our immune systems. It is a primary lymphoid organ that functions as the initial site of $\mathrm{T}$ cell immune maturation development. $\mathrm{T}$ cells gain their name as they mature in the thymus ${ }^{(1,2)}$. The thymus is a soft bilobed organ located in the superior mediastinum and close to the pericardium, anterior to the great vessels of the heart, and deep to the sternum. It extends from the level of the inferior poles thyroid gland above, to the fourth costal cartilage. Parallel to the gland on its left and right side are the phrenic nerves ${ }^{(3,4)}$. The thymus develops from the third pharyngeal pouch. Its development starts around embryonic day ${ }^{(5,6,7)}$. In children, $\mathrm{T}$ cells

Corresponding Author:- Huda Hussein Abd Fayr

Address:-Department of Human Anatomy, Section of Histology\& Embryology, University of 1072 
densely populate and develop in the cortex of the thymus. They pass to the medulla, before they are released into the circulation. At the age of adolescence, the thymus gland begins to atrophy.

Many factors play their role in involution process, the level of circulating hormones in the blood i.e. sex hormones also cause the gland to atrophy and is replaced by fat ${ }^{(8,9,10)}$. The sexual maturation of the mice become at $7-8$ weeks of age. The mice are continuously polyestrous and have an estrous cycle with length about 4-5 days according to ${ }^{(11)}$. Starvation mode is a state in which the body responds to prolonged periods of low energy intake. Its response in animals is a set of adaptive biochemical and physiological changes that reduce metabolism in response to a lack of food ${ }^{(12)}$. Immunohistochemistry is a technique used to check the specific protein or antigen $(\mathrm{Ag})$ present in the tissue using a specific biotinated antibody $(\mathrm{Ab})$, thereby allowing visualization under a microscope; to provide more precise of intra and extracellular localization of macromolecules; labeled antibodies with DAB are used for demonstrating both the presence and the molecular localization of an antigen (Ag) ${ }^{(13,14)}$. The CD326 is also known as epithelial adhesion molecule (EpCAM) ${ }^{(15)}$, the EpCAM (CD326) is expressed on the majority of reticular epithelial cells. The epithelial cells in the thymus show EpCAM expression, the CD326 is known as EGP40 (epithelial glycoprotein 40), 17-1A antigen, it also related to cancer as tumor-associated calcium signal transducer1 (TACSTD1) ${ }^{(16)}$. The stress factors that affect the immune system resulting in disorganization of the histological architecture of concerned organs, immune suppression, poor production and mortality. ${ }^{(17)}$

\section{Materials and methods:-}

Experimental animals and housing:-

The current study was conducted on ten (10) adult female mice (albino mice), aged about 10-12 weeks, weighing between 20-30 g, collected from National Center for Drug Control and Research. These kept under conventional condition in a clean and well ventilated room with free access to water (fresh tap water) and food (standard pellet diet) and maintained under a $14 \mathrm{~h}$ light $: 10 \mathrm{~h}$ darkness cycle and constant temperature $\left(25 \pm 2{ }^{\circ} \mathrm{C}\right)$. Then a random sample of the offspring will be selected and divided as follow in to two groups of animals:

1. Group (A): Control groups consists of (20) litters newborn age (1, 7, 14 and 30 days) each groups (5)litters newborn, (include the offspring who milk bottle- fed with the normal daily requirements).

2. Group (B): Starvation groups consists of (15) litters newborn age (7, 14 and 30 days ) each groups (5)litters newborn include the offspring who milk bottle- fed)with low calories diets, just $50 \%$ of the normal daily requirements .

\section{Sampling and tissue Preparation:-}

The animals euthanized by chloroform. Then the thymus gland was removed under a dissection microscope. After dissection, thymuses were transferred to $10 \%$ neutral buffered formalin (NBF) to obtain paraffin section for 48 hours ${ }^{(18)}$. The samples became ready for histological preparation of fixation, dehydration,clearing, paraffin embedding and sectioning dewaxing and hydration. All according to (Bancroft et al., 2018). ${ }^{(19)}$

\section{Immunohistochemistry:-}

The Super Sensitive IHC for Detection Kit (orb219874) EPCAM Receptor 2 antibody (orb378758) Ag were found in thymus gland by following all subsequent steps, which carried out at room temperature in a humidified chamber. Super Sensitive IHC Detection Kit (orb219874) was used. Sectioning at $5 \mu \mathrm{m}$ were used and deparafinization, Incubate tissue in appropriate pretreatment or digestive enzyme for primary antibody, digestive enzyme use (pepsin enzyme); and PBS/TBS wash 3 times for 2 minutes. Then incubate slide in Hydrogen Peroxide Blocking Reagent for 10 minutes, PBS/TBS wash 3 times for 2 minutes. Apply Blocking Reagent and incubate for 5 minutes, PBS/TBS wash 3 times for 2 minutes (May be omitted if primary antibodies are diluted in buffers containing normal goat serum). Apply primary antibody and incubate according to manufacturer's recommended protocol (overnight) incubation, PBS/TBS wash 3 times for 2 minutes. Apply HRP Polymer and incubate for 10 minutes, PBS/TBS wash 3 times for 2 minutes. Add $20 \mu 1$ of DAB Chromogen to $1 \mathrm{ml}$ of DAB Substrate, mix by swirling and apply to tissue. Incubate for about 3 - 5 minutes, PBS/TBS wash 3 times for 2 minutes. Finally counter stain and cover slip using a permanent mounting media.

\section{Statistical Analysis:-}

The Statistical package for social sciences (SPSS) program was used to effect of difference factors in study parameters . For differences between the mean percentages of the cells ( RECs ) of thymus gland ( for experimental starvation group and control group) were examined for statistical significance using ANOVA with Tukey test shows the difference in the mean positively \pm stander error (SE) between control group and experimental starvation group 
was used to measure the significance of differences in the mean number, of positive pixels of immunohistochemical reactivity of EPCAM marker ${ }^{(20)}$.

\section{Results:-}

Immunohistochemical IHC Study of EPCAM receptor2 antibody (orb378758):-

EPCAM receptor $2 \mathrm{Ab}$ was used to demonstrate EPCAM reactivity in thymus gland and to quantify the differences of activity of those cells between the starvation and control groups. EPCAM distribution in both experimental groups and control groups revealed that variant expression distribution was present in the all layers of thymic gland, which surround differentiated thymocytes forming a nurse cell, and the expression of EPCAM receptor 2 Ab was observed in the cell membrane of the reticular epithelial cells. The nuclei component stained with counter stain Harris Hematoxylin, the reaction was ranging between positive and strong positive reaction in control group,

In the aperio program observation the reaction between the anti EPCAM receptor $2 \mathrm{Ab}$ and RECs was representted by different degrees of the strength of positivity of Anti EPCAM receptor $2 \mathrm{Ab}$. The reaction was homogenous in cell membrane of thymus gland in control groups Fig. $[(1,2,3,4) A \& B]$, and starvation groups Fig. $[(5,6,7)$ A\&B].

So that the EPCAM receptors activity was abundant in subcapsular, cortical, corticomedullary area and medullary more in control group than in experimental starvation group [Fig: (4-20)A], Reticular epithelial cells showed an intense reactivity toward EPCAM receptors $2 \mathrm{Ab}$, the reaction was ranging between positive and strong positive reaction in control group [Fig: 4-20) C].

It was observed that epithelial reticular cells in the starvation groups were gradually decreasing $(7,14$, and 30$)$ days comparison to control group $(1,7,14$, and 30)days. The immuno- histochemical result of marker expression of EPCAM receptor in reticular epithelial cells (RECs) showed decrease in values of the mean positivity \pm stander error in the experimental starvation groups the picture different the reaction intensity was very weak ranged between negative and weak positive and it was not possible to identify the cell margins of reticular epithelial cells( RECs) [Fig. $(5,6,7) \quad A \& B]$. In comparison to control groups which high detection of anti EPCAM in RECs Fig. $[(1,2,3,4) \mathrm{A} \& \mathrm{~B}]$.

The degree of positivity measured by using Aperio program and this program showed different color in regards to the intensity of the reaction:

1. The strong positivity appears in a brown color.

2. The positivity appears in orange color.

3. The weak positivity appears in yellow color.

4. The negative appear in blue color.

5. The white colors indicate no tissue in the sections.
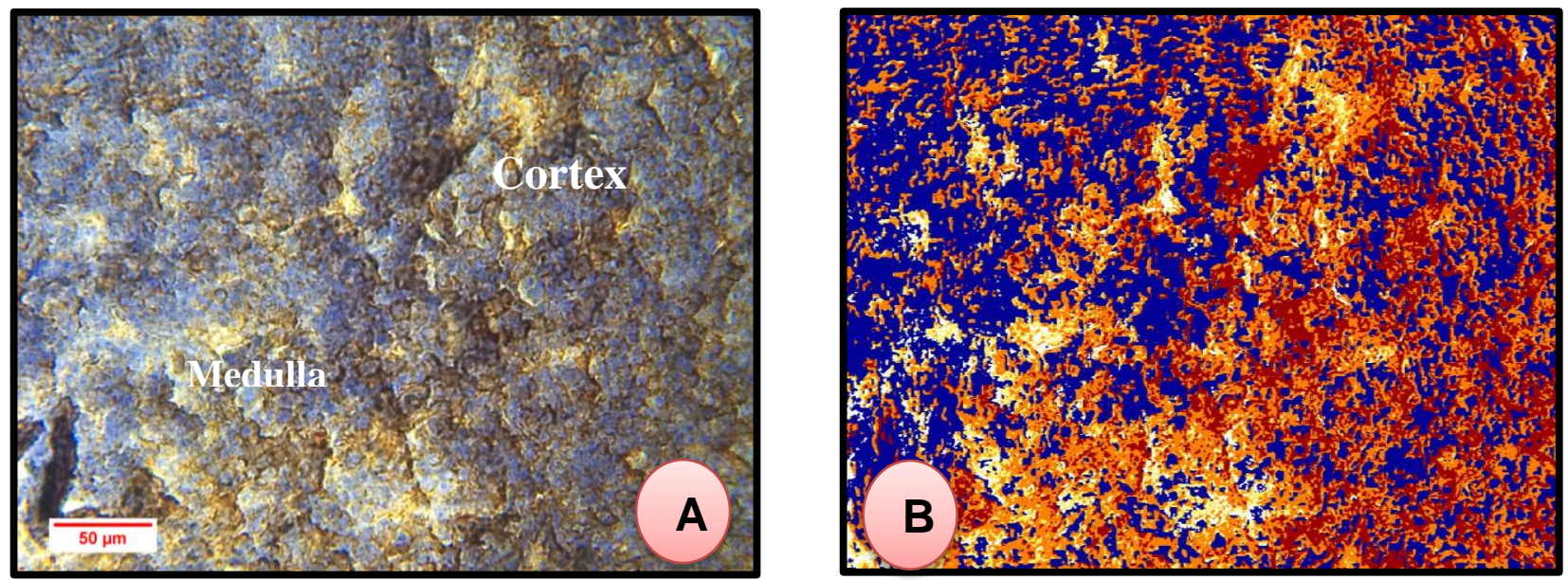

(Figure: 1) A:-Section in the thymus gland show RECs in cortex and medulla of control group (1 day ) high detection of anti EPCAM, EPCAM IHC, X40.B: Mark up image show the positivity reaction represented in brown color, weak positive represented in yellow color and negative represented in blue color. 

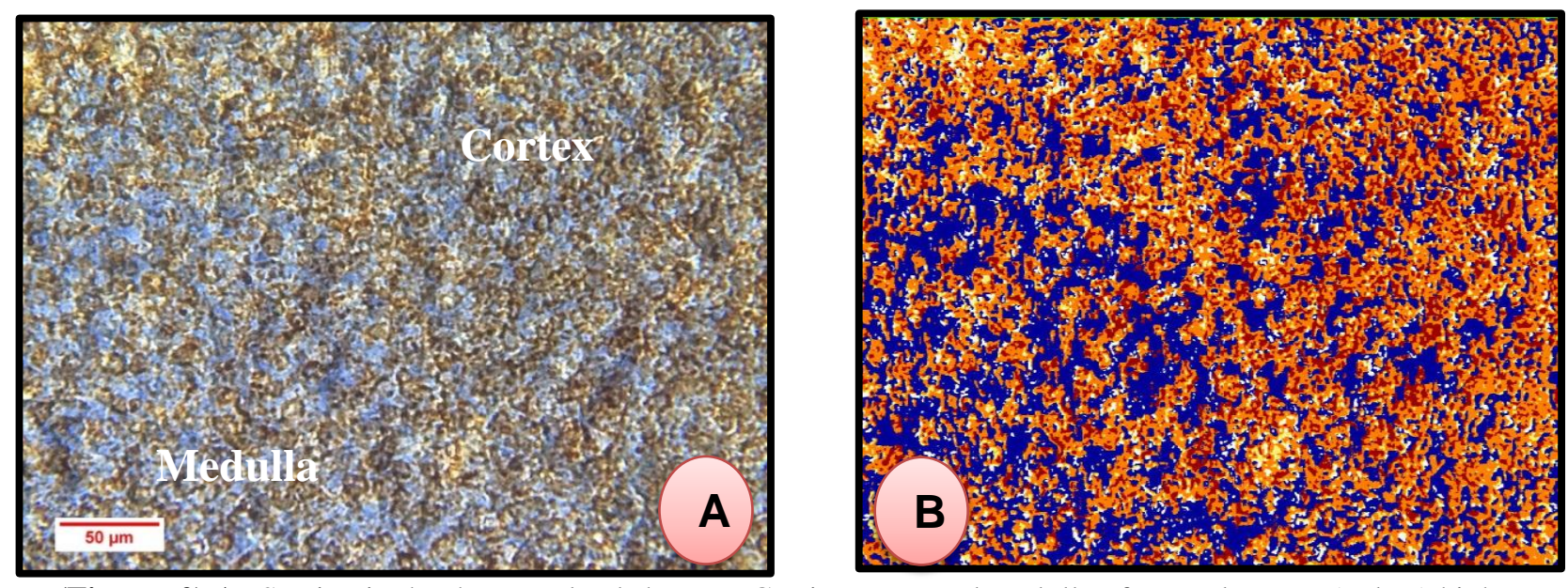

(Figure: 2) A:-Section in the thymus gland show RECs in cortex and medulla of control group (7 day ) high detection of anti EPCAM, EPCAM IHC, X40.B: Mark up image show the positivity reaction represented in brown color, weak positive represented in yellow color and negative represented in blue color.
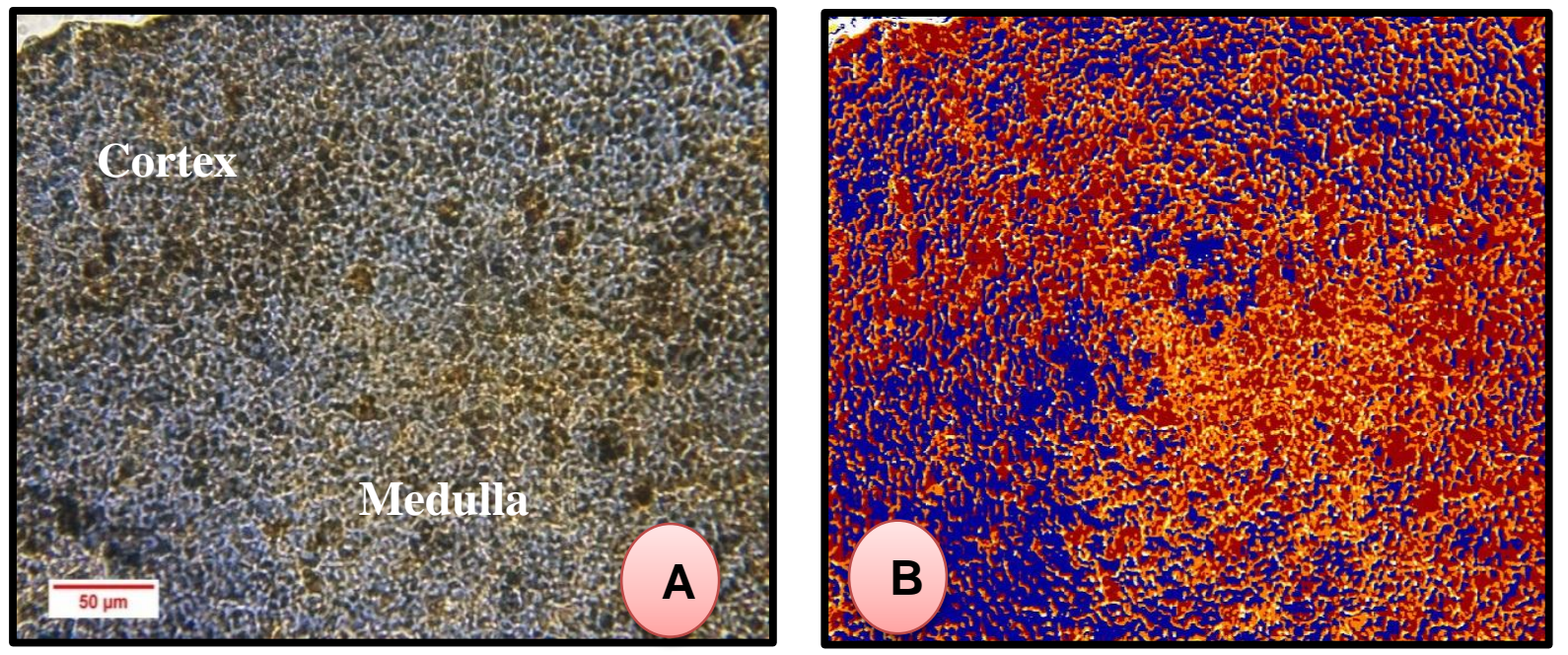

(Figure: 3) A: Section in the thymus gland show RECs in cortex and medulla of control group (14 days ) high detection of anti EPCAM, EPCAM IHC, X40.B: Mark up image show the positivity reaction represented in brown color, weak positive represented in yellow color and negative represented in blue color. 

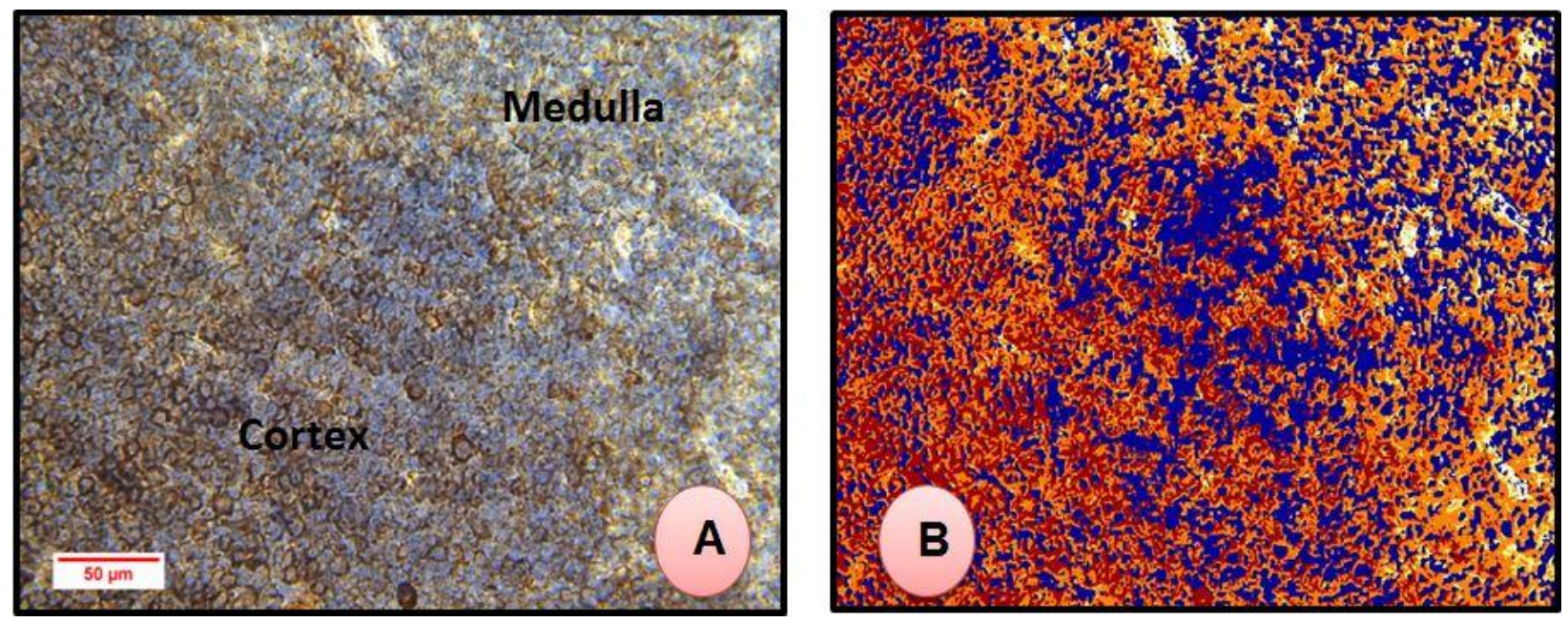

(Figure: 4) A:-Section in the thymus gland show RECs in cortex and medulla of control group (30 days ) high detection of anti EPCAM, EPCAM IHC, X40.B: Mark up image show the positivity reaction represented in brown color, weak positive represented in yellow color and negative represented in blue color.
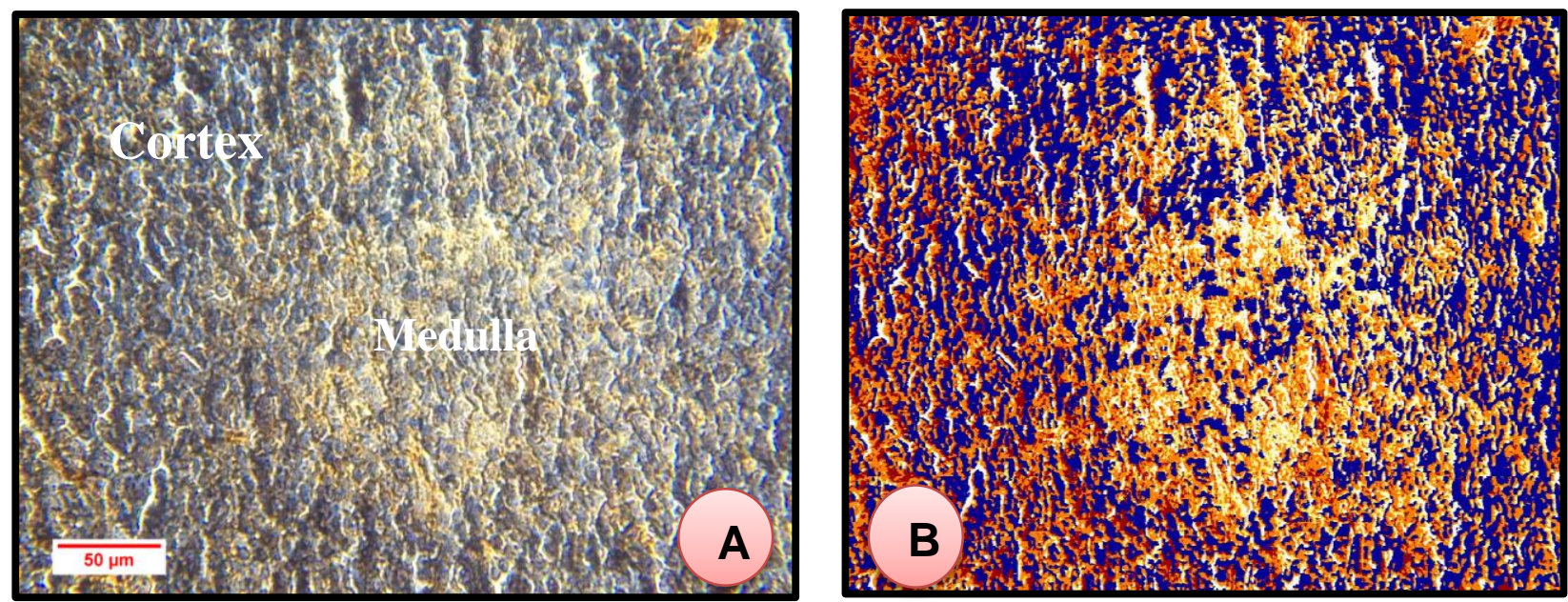

(Figure: 5) A: Section in the thymus gland show RECs in cortex and medulla of starvation group (1 day) decrease detection of anti EPCAM , EPCAM IHC, X40.B: Mark up image show the positivity reaction represented in brown color, weak positive represented in yellow color and negative represented in blue color.
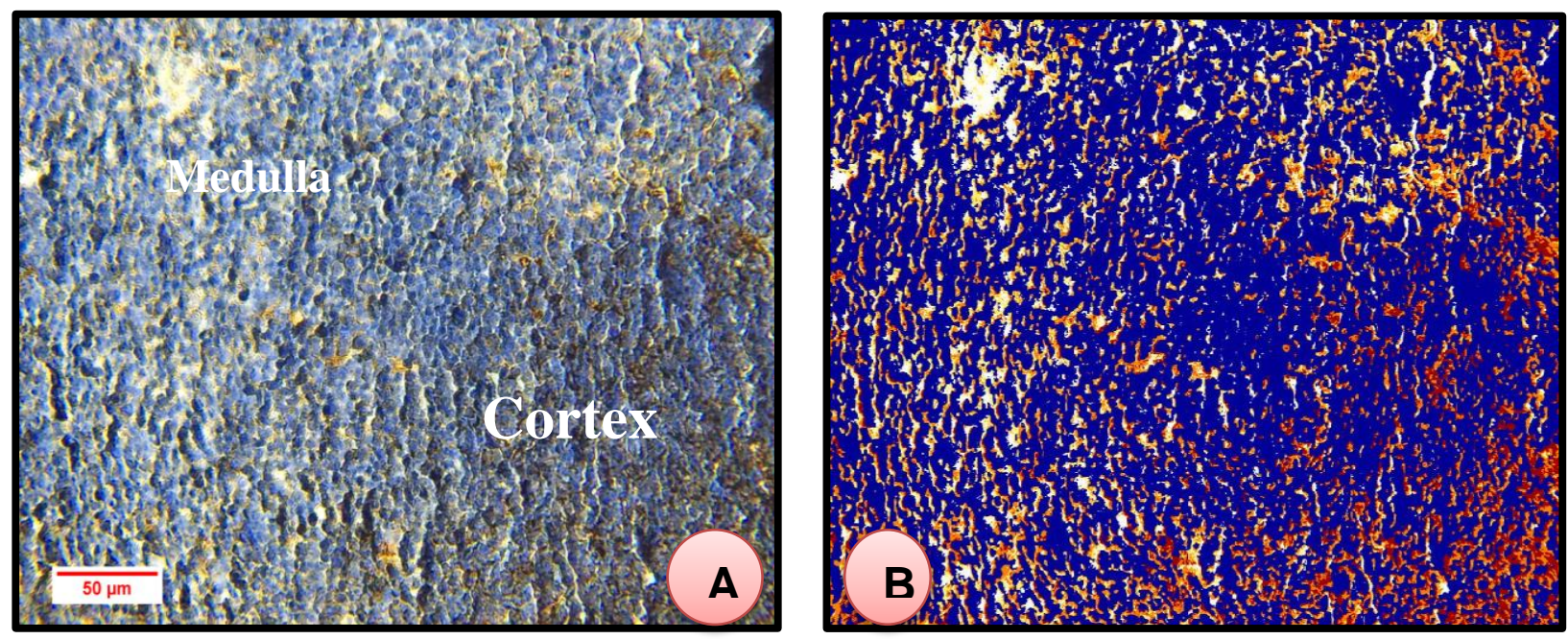
(Figure: 6) A: Section in the thymus gland show RECs in cortex and medulla of starvation group (14 days ) decrease detection of anti EPCAM gradually, EPCAM IHC, X40.B: Mark up image show the positivity reaction represented in brown color, weak positive represented in yellow color and negative represented in blue color.

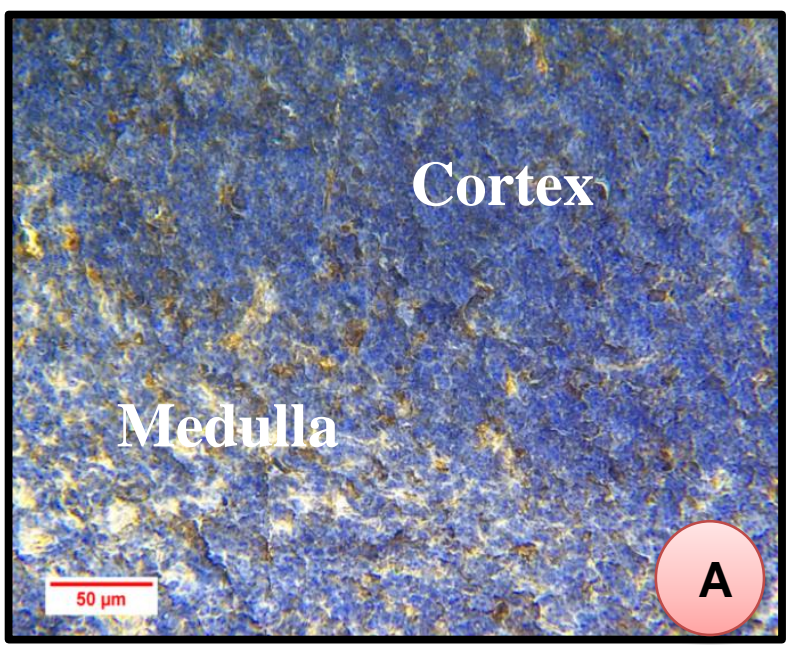

(Figure: 7) A: Section in the thymus gland show REC

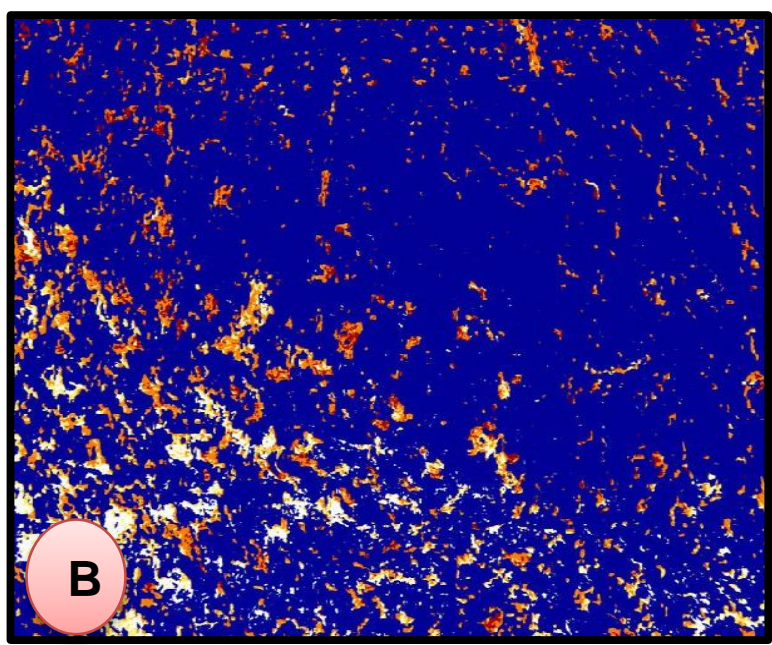

in cortex and medulla of starvation group (30 days) decrease detection of anti EPCAM gradually, EPCAM IHC, X40.B: Mark up image show the positivity reaction represented in brown color, weak positive represented in yellow color and negative represented in blue color.

\section{Morphometrical Analysis of Immunohistochemical Reactivity of EPCAM receptor 2 Ab:-}

The staining reactivity of EPCAM receptor $2 \mathrm{Ab}$ was represented by calculating the mean positivity percentage in the paraffin sections for both (starvation and control ) groups; the staining reactivity was high in control group than those in starvation groups. The staining reactivity of anti- EPCAM receptor $2 \mathrm{Ab}$ in RECs of thymus gland in control group show high difference in positivity. There was strong positive reactivity in cell membrane of RECs in control group. On the other hand, the reactivity in cell membrane of RECs that is weakly positive in starvation groups. Table [1] \& (Figure: 8).

Table 1:-Show the difference Strength of positivity of EPCAM Receptor 2 Ab of thymus gland in control and experimental starvation groups.

\begin{tabular}{|c|c|c|}
\hline Groups & Mean \pm SE pixel /(micron $)^{\mathbf{2}}$ & P value \\
\hline D1 & $0.331 \pm 0.027$ & \multirow{2}{*}{ P $\leq \mathbf{0 . 0 5}$} \\
\hline D7C & $0.378 \pm 0.036$ & \\
\hline D7S & $0.324 \pm 0.015$ & \\
\hline D14C & $0.397 \pm 0.019$ \\
\hline D14S & $0.292 \pm 0.022$ \\
\hline D30C & $0.425 \pm 0.012$ & \\
\hline D30S & $0.256 \pm 0.017$ & \\
\hline
\end{tabular}




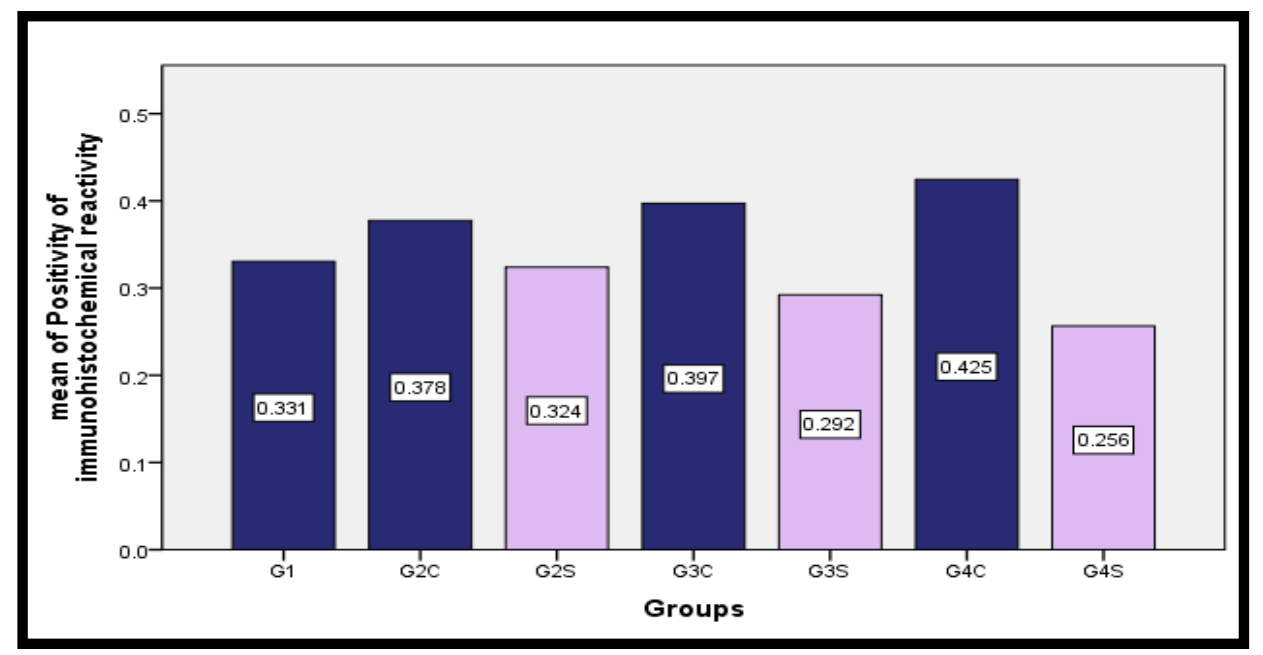

Figure: 8:-Histogram shows the difference reactivity of EPCAM receptor $2 \mathrm{Ab}$ of thymus gland in control and experimental starvation groups.

\section{Discussion:-}

The epithelial cell adhesion molecule (EPCAM) receptors are present in thymus gland cells (reticular epithelial cells) to determine their activity during thymic cells development and even in starvation state of experimental animals(mice), The EPCAM receptor in thymus gland stain the reticular epithelial cells and observed in control groups as trabecular like arrangement of thymocytes ( represent the line of migration ) from medullary to cortical area in 1 days of control group. While control groups in 7,14 and 30 days there are increased markers expression in RECs due to maturity. While in experimental starvation group in 7, 14 and 30 days we notes decreased in marker expression of RECs in thymus gland due to stress effect of starvation on neonate mice thymic cells development.

In the present study the EPCAMs distribution in both experimental and control groups revealed that variant expression and distribution was present in all layers of thymic gland, which support and protect the immature thymocytes forming what is called nurse cell. The expression of this EPCAM is observed in the cell membrane of the reticular epithelial cells. These nurse cells have pivotal role in proliferation, differentiation and maturation of thymocytes before migration to peripheral circulation from thymus and take its duty as cell mediated immunity. This agree with (Schmelzer and Reid, 2008) ${ }^{(21)}$ who found that the EPCAM which is present in cell membrane of RECs, This epithelial cell adhesion molecule (EpCAM), was originally identified as a marker for carcinoma, attributable to its high expression in rapidly proliferating tumors of epithelial origin. Normal epithelial cells expressions EpCAM at a variable but generally basal low level than that in carcinoma cells. The role of EpCAM is not limited only to cell adhesion but includes in diverse processes of signaling cell (REC) for proliferation, differentiation and migration to its final destination. Cell surface expression of EpCAM may actually prevent cell-cell adhesion ${ }^{(22)}$ identified functions of EpCAM in view of its prognostic relevance in carcinoma, inflammatory pathophysiology, and tissue development and regeneration as well as its role in normal epithelial homeostasis. Moreover, other researchers found that EpCAM modifies cell-cell contact adhesion strength and tissue plasticity, and how it regulates cell proliferation and differentiation. Mutant EpCAM that is absent from the cell surface leads to fatal intestinal abnormalities which lead to cell proliferation in cancer may result from signaling ${ }^{(23)}$. In the present study the distribution and the expression of EPCAM was observed in the cell membrane of the reticular epithelial cells, and has vital role in proliferation and differentiation of thymocytes before migration to peripheral circulation. While ( Reza and Ritter, 1994) ${ }^{(24)}$ found that these membranous protein mediators assist in development of a diverse self-tolerant T-cell repertoire occurs within the thymus, and requires contact between developing $\mathrm{T}$ cells and their stromal microenvironment. This interactions depend on the combined effect of specific adhesion molecules, as a preliminary step to determine their role in T-cell development.

In the present study in control group the EPCAM receptors activity was abundant in subcapsular, cortical and corticomedullary area while less evident in the medullary area of thymic gland. These indicate that TECs are important in maturation of thymocyte in above mentioned areas in the thymus and this result agrees with (Sun et al 
., 2013) ${ }^{(25)}$ who found that TECs, composed of cortical and medullary TECs, are derived from a common bipotent progenitor, mediating thymocyte positive and negative selections. Multiple levels of signals including intracellular signaling networks and cell-cell interaction are required for TEC development and differentiation.

In the present study in control group the EPCAM protein receptor in present study is applied as marker expression on the cell membrane of TECs and even thymocytes which indicate maturation and differentiation event and aspect of thymic cells. This disagree with authors (Spizzo et al., 2011) ${ }^{(26)}$ who found that EpCAM fraction of the thymic stroma is commonly considered to be the distinguishing marker of epithelial cells (TECs) within the thymus. EpCAM expression has been also detected in nonepithelial cells, such as thymocytes which suggests that EpCAM expression cannot be considered as a bona fide marker of epithelial cell identity.

\section{Conclusion:-}

The EPCAM receptor reactions in the reticular epithelial cells during development of thymic gland and have low reactivity in starvation groups compare with control groups. The EPCAM receptor 2 was specific expressed in reticular epithelial cells (RECs) without other than. Detection of EPCAM has prognostic value ( relevance)in: Carcinoma, Inflammatory pathophysiology, Tissue development (present study), Regeneration, Normal epithelial homeostasis and Degeneration (apoptosis).

\section{Acknowledgment:-}

I would like to express my sincere gratitude to my supervisor Prof. Dr. Haider A. Jaafar for his suggestion this work, his patience, great support, generous help and continuous guidance throughout the course of study. I would like to thank Dr. Hussein A. Jarallah for his assistance and support. Also I would like to thank all the members of the department of Human Anatomy, Histology \& Embryology at the College of Medicine /Al-Nahrarain University for their kind help and support.

\section{References:-}

1. Condie, N. R. M. B. G., and B. G. Condie.( 2010). Transcriptional regulation of thymus organogenesis and thymic epithelial cell differentiation. Prog. Mol. Biol. Transl. Sci. 92: 103-120.

2. Rode, I., Martins, V. C., Küblbeck, G., Maltry, N., Tessmer, C., \& Rodewald, H. R. (2015). Foxn1 protein expression in the developing, aging, and regenerating thymus. The Journal of Immunology, 195(12), 5678-5687.

3. Moore, K. L., Dalley, A. F., \& Agur, A. M. (2013). Clinically oriented anatomy. Lippincott Williams \& Wilkins (161)( 191-1170).

4. Zuckerwise, Lisa C., Li, L., \& Copel, J. A. (2018). Thymus. In Obstetric Imaging: Fetal Diagnosis and Care (Second Edition)(pp. 25-28). e1.

5. Itoi, M., Kawamoto, H., Katsura, Y., \& Amagai, T. (2001). Two distinct steps of immigration of hematopoietic progenitors into the early thymus anlage. International immunology, 13(9), 1203-1211.

6. Gordon, J., \& Manley, N. R. (2011). Mechanisms of thymus organogenesis and morphogenesis. Development, 138(18), 3865-3878.

7. Junqueira, L. C., Mescher, A. L \& Carneiro, J. (2013). Basic histologytext and atlas. London: McGraw Hill, 65$85,287-297$.

8. Rizzo, Donald. C. (2015). Fundamentals of anatomy and physiology. Cengage Learning , p ( 371 ), (358- 515)

9. Schiaffino, S., Mammucari, C., \& Sandri, M. (2008). The role of autophagy in neonatal tissues: just a response to amino acid starvation?. Autophagy, 4(5), 727-730.

10. Anastasiadis, K., \& Ratnatunga, C. (Eds.). (2014). The thymus gland: diagnosis and surgical management. Springer Science \& Business Media., P ( 5- 112 ) .

11. Danneman, P. J., Suckow, M. A., \& Brayton, C. (2012). The laboratory mouse. CRC Press. 5, 21-45.

12. Wang, T., Hung, C. C., \& Randall, D. J. (2006). The comparative physiology of food deprivation: from feast to famine. Annu. Rev. Physiol., 68, 223-251.

13. Duerr, J. S. (2006). Immunohistochemistry.

14. Dabbs, David J. (2018)Diagnostic Immunohistochemistry E-Book: Theranostic and Genomic Applications. Elsevier Health Sciences.

15. Patriarca C, Macchi RM, Marschner AK, Mellstedt H.. Epithelial cell adhesion molecule expression (CD326) in cancer: a short review.. Cancer Treat Rev. 2012; 38(1):68-75. 
16. Farr, A. N. D. R. E. W., Nelson, A. N. D. R. E. W., Truex, J. I. L. L., \& Hosier, S. U. Z. A. N. N. E. (1991). Epithelial heterogeneity in the murine thymus: a cell surface glycoprotein expressed by subcapsular and medullary epithelium. Journal of Histochemistry \& Cytochemistry, 39(5), 645-653.

17. Hussan MT, Khan MZI, Lucky NS (2009) Immunohistochemical study of the postnatal development of lymphoid tissues and mucosa of broilers. Bangl J Vet Med 7(1): 253-258.

18. Treuting, P. M., Dintzis, S. M., Liggitt, D., \& Frevert, C. W. (Eds.). (2011). Comparative anatomy and histology: a mouse and human atlas (expert consult). Academic Press.

19. Bancroft, J. D., Floyd, A. D., \& Suvarna, S. K. (2018). Bancroft's Theory and Practice of Histological Techniques,53, 83, 93, 105-121, 433-517.

20. Babbie, E., Wagner III, W. E., \& Zaino, J. (2018). Adventures in social research: Data analysis using IBM® SPSS® Statistics. Sage Publications.

21. Schmelzer, E., \& Reid, L. M. (2008). EpCAM expression in normal, non-pathological tissues. Frontiers in bioscience: a journal and virtual library, 13, 3096-3100.

22. Trzpis, M., McLaughlin, P. M., de Leij, L. M., \& Harmsen, M. C. (2007). Epithelial cell adhesion molecule: more than a carcinoma marker and adhesion molecule. The American journal of pathology, 171(2), 386-395.

23. Schnell, U., Cirulli, V., \& Giepmans, B. N. (2013). EpCAM: structure and function in health and disease. Biochimica et Biophysica Acta (BBA)-Biomembranes, 1828(8), 1989-2001.

24. Reza, J. N., \& Ritter, M. A. (1994). Differential expression of adhesion molecules within the human thymus. Clinical and Developmental Immunology, 4(1), 55-64.

25. Sun, L., Luo, H., Li, H., \& Zhao, Y. (2013). Thymic epithelial cell development and differentiation: cellular and molecular regulation. Protein \& cell, 4(5), 342-355.

26. Spizzo, G., Fong, D., Wurm, M., Ensinger, C., Obrist, P., Hofer, C., ... \& Went, P. (2011). EPCAM expression in primary tumour tissues and metastases: an immunohistochemical analysis. Journal of clinical pathology, 64(5), 415-420. 